\title{
Biological, Physico-Chemical and Morphological Analyses of Four Biochars Derived from Agricultural Waste
}

\author{
Dounia Fetjah ${ }^{1 *}$, Lalla Fatima Ezzahra Ainlhout ${ }^{2}$, Bouchaib Ihssane ${ }^{3}$, \\ Abdellah Houari ${ }^{4}$, Zaina Idardare ${ }^{5}$, Laila Bouqbis ${ }^{2 *}$ \\ 1 Faculty of Sciences, Ibn Zohr University, Agadir, Morocco \\ 2 Faculty of Applied Sciences, Ibn Zohr University, Ait Melloul, Morocco \\ ${ }^{3}$ Sidi Mohamed Ben Abdellah University, Faculty of Sciences and Techniques, Fès, Morocco \\ ${ }^{4}$ Polydisciplinary Faculty, Ibn Zohr University, Taroudant, Morocco \\ ${ }^{5}$ Higher Institute of Maritime Fisheries, Agadir, Morocco \\ *Corresponding author's email: fetjahdounia194@gmail.com; laila.bouqbis@gmail.com
}

\begin{abstract}
Around the world, the increasing population and consumption are placing huge demands on food. Agriculture is considered one of the important sectors in the world and the force to feed humanity. While under these circumstances, which stand out by successive years of drought, degradation of soil, climate change, and global warming, this sector has multifaceted a major issue that goes beyond threatening food security. Thus, Morocco characterized by an arid and semi-arid climate is one example of countries that suffered from those problems. Due to lack of rain, the water resources of some Moroccan arable lands are consumed highly as well as the quality of its soils is now degraded. This issue calls for new approaches to amending the degraded soils in these regions and sustain water supplies. Indeed, biochar can be a remedy for these poor soils; in fact, it has an incredible sequester carbon on soil, a benefit on the environment as well as on plant growth. Despite its virtues, certain biochars contain phytotoxic compounds. In this study, four biochars prepared from banana waste, peanut hull, almond shells, and walnut shells were tested on three plant species (cress to test (HAP), barley for assessing heavy metals, and lettuce to assess salinity) before any field application. The chemical and physical analysis was done for the four biochars and the sandy soil, the four biochars were also analyzed by scanning electron microscopy (SEM) for identifying the morphology of each biochar. The results showed that the four biochars enhanced water holding capacity (WHC), they also revealed the existence of heavy metals especially for almond shells biochar and walnut shells biochar. While for the morphology of each biochar, banana waste biochar (BC-BW) and peanut hull biochar (BC-PeH) had more pores than almond shells biochar (BC-Alm) and walnut shells biochar(BC-WS). Concerning the phytotoxic tests, the lettuce was germinated in all biochars treatments except for the $8 \%$ biochar banana treatment, for the cress and barley, all the treatments were grown.
\end{abstract}

Keywords : banana waste, peanut hull, almond and walnut shells, phytotoxic test, SEM, PCA study and Scheffe test

\section{INTRODUCTION}

In the last decades, the increase in population anticipated unprecedented demands on food. Agriculture is one of the essential sectors in the world and an important source of food provision for humanity (Tamburino et al. 2020; Foley et al. 2011). Due to this intensification, farmers used a lot of fertilizers to sustain food security.
Therefore, agriculture has already suffered from major global environmental impacts: degrading soil, successive years of drought, climate change, and global warming (Saeed et al.2014). Thus, Morocco is an agricultural country that has diverse crops produced each year due to the favorable climate. Besides, it is taking an incredible reputation in exporting and shipping fruits and vegetables in the universal markets. For instance, 
in 2018, Morocco was the third African country which shipped banana by a quantity of 26.3 thousand tonnes, and an export that exceeded nineteen million tonnes (Banana Market Review Prelim Results, FAO, 2018), not only the cultivation of fruits, Morocco has succeeded to cultivate 25.000 ha of peanut on its sandy soils in the Atlantic coast between kenitra and Larache, also, the production of almond in morocco takes the fifth rank, around the world (Agronomic and veterinary institute in September 2011, Mahhou et al. 1992). Besides, in the area of 4500 ha, Morocco produced 7000 tons of common unshelled walnut (juglans Regia) per year (Agronomic and veterinary institute II, 2006). Despite these virtues, all these crops generate a lot of agricultural residues, and disposal of these wastes is costly. Some of these cultural residues are utilized for burning or composting (Chanakya et al. 2012; Peigné et al. 2004). The two ways are the most used in terms of reducing the volume of agricultural wastes. Otherwise, in some African countries, the use of peanut hulls as feed for animals is also considered a method to benefit from peanut wastes (Boudergues et al. 1970). Even though the profits and benefits of all these methods to reduce agricultural waste, still harm the environment such as air pollution and non-use of energy, and affect the quality of water (Darley et al. 1966). All these drawbacks let us think of other, more profitable, and sustainable methods such as pyrolysis to produce biochar. The history of biochar had existed for thousands of years, moreover, the use of charcoal has been long known in Brazilian soils, it is a black carbon-rich of organic matter soil with higher nutrients such as phosphorus, nitrogen, calcium, and potassium. Indeed, the black carbon can be considered as a carbon sink, which gives terra preta soils the ability to sustain fertility in soils (Glaser et al. 2001).

Plus, several studies had interested in biochar benefits, it has been shown that the application of biochar increased plant growth and microbial activity (Cui et al. 2013; Zhang et al. 2016) Also, it can be considered as an amendment for soil, as well as it helps to enhance soil fertility (Glaser et al. 2002). Moreover, it can mitigate global warming and restore degraded lands (Barrow et al. 2012, Inyang \& Dickenson 2015). In contrast, certain biochar can be contaminated by heavy metals (inorganic contaminants) or organic ones such as polycyclic aromatic hydrocarbons (PAH) as well as dioxins and furans (Kołtowski et al.
2015). That's why before any large-scale field application, biochar should be tested if it is toxic or neither. In this study, we applied pyrolysis to four types of biomass; the choice of the four feedstocks was depended on the local waste that leftover from all over our country: almond shells and walnut shells were from the center of Morocco, peanut hull from the west of Morocco, and banana waste was collected from the southwest of Morocco.

The aims of this study were: (a) To examine the toxicity of the four biochars by phytotoxic tests (HAP, heavy metals, and salinity); (b) To test the ability of soil to retain water when mixed with these types of biochar with different concentrations; (c) and to compare the porosity of the four biochars.

\section{MATERIALS AND METHODS}

\section{Preparation of biochar}

Four different biomass were used from four feedstock materials: Almond Shells (Alm); Walnut Shells(WS), peanut hull(PeH), and Banana waste (BW). Firstly, the samples were dried in the air. The artisanal dry pyrolysis biochar was made at four different temperatures $(343,256$, $198,201^{\circ} \mathrm{C}$ ) respectively (Bouqbis et al. 2016). The temperature was measured by infrared thermometer Wintact WT900.

\section{Water holding capacity}

The soil used in this experiment was sand for the salad germination test and peat for the barley test. Small proportions of biochar $(0,0.5,1$, $2,4,6$, and $8 \%$ ) were mixed to fine Sand. The sort that $0.5 \%$ refers to $0.5 \mathrm{~g}$ dry of biochar added to $95.5 \mathrm{~g}$ dry sand. $0 \%$ sand sample was considered as control. $40 \mathrm{~g}$ of fresh weight of distinct mixture samples was filled in small tubes, $5.5 \mathrm{~cm}$ high, and 3.6 diameters. Then, all tubes were put into a plastic box that was filled with tap water in a way that sand got saturated, and immersed in water for $24 \mathrm{~h}$. The box was wrapped in aluminum foil. After $24 \mathrm{~h}$, water was dropped out by placing tubes on test tube racks. All treatments were replicated three times. The same protocol was applied for different treatments and for the barley test with different percentages (peat only which was considered as control, $2.5 \%, 10 \%$ and $25 \%$ ). 


\section{Phytotoxic test germination}

Three phytotoxicity tests were done to assess biochar toxicity. Four types of biochars were tested: banana waste, peanut hull, almond shells, and walnut shells. All biochars were produced by pyrolysis following procedures of (Bouqbis et al. 2016; Bouqbis et al. 2017). In this experiment, three species were used: cress (Lepidium sativum, L.), barley (Hordeum vulgare), and salad (Lactuca sativa L.).

For cress germination, we germinated $0.5 \mathrm{~g}$ cress seeds (Lepidium sativum, L.) on two wet pads of cotton above wire on the upper of a (200 $\mathrm{mL}$ ) glass filled with a mixture of $100 \mathrm{~g}$ dry weight of substrate and water. Water holding capacity was stable at $30 \%$. The little glasses were put into $1 \mathrm{~L}$ glasses and $20 \mathrm{~mL}$ of tap water was added. The protocol was described by (Busch et al. 2012. and Bouqbis et al 2016, 2017, 2018). After 7 days, the harvest took place, we measured the fresh and dry weight of cress, as well as, the length of hypocotyl was rounded in centimeter.

Concerning barley germination test, we used the protocol of Busch et al. 2012, the four concentrations of biochar were $(1 \%, 2.5 \%, 5 \%$, and $10 \%)$. The mix was made up of peat and biochar. The dry weight, as well as the WHC of all treatment substrates, was determined. Afterward, the WHC was $60 \%$. We divided the mixture of each treatment into four pots and we placed it in the bottom of it, then we sowed 20 barley seeds (Hordeum vulgare) on each pot and covered it with a little quantity of each mixture. The first weight of the whole pot plants was noted, during 9 days in every pot, we added the tap water in a way to adjust the water loss by evapotranspiration as a result we conclude the parameter of water use efficiency (WUE). After 9 days, the data of temperature and humidity for the four types of biochars was measured and then collected from a data logger also; in each pot of treatment, we noticed the weight of the fresh and dry weight. Besides, we counted all germinated to measure the germination rate of each treatment.

The lettuce test germination drew on the ISO-17126 norm standard to assess the toxicity of substances as well as their impacts on soils (Busch et al. 2012). We mixed sand with biochar following its amounts suggested by Busch $(0.5 \%$, $1 \%, 2 \%, 4 \%, 6 \%$ and $8 \%$ ). Before the test started the $\mathrm{pH}$ and conductivity of all treatment mixtures were measured. Each Petri dish contained $100 \mathrm{~g}$ of a sand mixture according to the appropriate percentage, in which 40 salad seeds were sown and humidified with $85 \%$ of its maximum WHC. After one week, the fresh weight and the germinate rate were determined. At the end of the test, the $\mathrm{pH}$ and conductivity of treatments were again measured (Bouqbis et al. 2017).

\section{Physical and chemical analyses}

The four biochars were first sieved at $2 \mathrm{~mm}$, then $\mathrm{pH}$ and electrical conductivity (EC) of all biochars were determined in water extracts with standard electrodes (Blakemore et al. 1987). Elemental analyses were carried out on the sand and the four biochars. The total $\mathrm{Na}, \mathrm{K}, \mathrm{Ca}$, and $\mathrm{Mg}$ contents were determined by a flame emission spectrophotometer (Van Rast et al. 1999). While the total concentration of $\mathrm{Fe}, \mathrm{Mn}, \mathrm{Zn}$, and $\mathrm{Cu}$ were taken by atomic absorption spectrophotometer (Lindsay and Norvell, 1978). The $\mathrm{KH}_{2} \mathrm{PO}_{4}$ and $\mathrm{NaNO}_{3}$ were measured using colorimetrical analyses (Blakemore et al., 1987; Lachat, 1998a; Lachat, 1998b). The total soil organic carbon and the total nitrogen (TN) content were measured using Walkley-black method and the Kjeldahl method, respectively.

\section{MORPHOLOGICAL ANALYSES}

\section{SEM and EDS analses}

The morphology and the elemental analysis of the four biochars were analyzed by scanning electron microscopy coupled with EDS (EDS/SEM) by FEI, Quanta 200-ESEM operated at $20 \mathrm{kV}$.

\section{Statistics}

One way ANOVA and Tukey's honest significant difference (HSD) was used to determine statistical of the differences between the four biochars and control in Lepidium test germination. While the multivariate approach of principal component analysis (PCA) was carried out to determine the effect of different parameters for barley test germination. For salad test germination we used twoway ANOVA and we found the groups obtained according to the "treatment" factor by the Scheffé contrast test, the significance was fixed at 5\%. All analyses were done by RStudio V1.3.1093. 


\section{RESULTS AND DISCUSSION}

\section{Water holding capacity}

The water-holding capacities were $0.29,0.36$, and $0.58 \mathrm{gH}_{2} \mathrm{O} \mathrm{g}^{-1}$ soil (dry weight) in $0 \%, 0.5 \%$, and $8 \%$ of banana waste biochar-sand mixture, meaning that banana waste biochar had the highest efficiency in increasing the WHC by $19.4 \%$ and $50 \%$ comparatively with control. While, peanut hull biochar mixed with sand was $0.29,0.32$, and 0.41 for water holding capacities and less effect of increasing comparing to banana biochar, with $9.375 \%$ and $29,26 \%$ improvement. Indeed, the water holding capacity was improved with the walnut shells $0 \%$ and $20.69 \%$ of the increase. For Almond shells, water holding capacity was 0.29 , 0.29 and $0.38 \mathrm{gH}_{2} \mathrm{O} \mathrm{g}^{-1}$ soil (dry weight) in $0 \%$, $0.5 \%$, and $8 \%$. The increase in the mixture of sand and biochar was $0 \%, 31.03 \%$ respectively.

Many researchers would go that biochar can be considered as a double-edged sword; indeed some biochar showed a positive effect on enhancing the water holding capacity of soils, while other biochars had negative effects. Our peanut hull biochar has increased the WHC in the sand mixture in the salad germination test. This means that our results go in line with a study conducted by (Kammann et al. 2011) on which they found that peanut hull had significantly improved WHC in poor sandy soil and enhanced the yield of crop quinoa (Chenopodium quinoa). Also, we found that our banana waste biochar had increased the water holding capacity.

\section{Phytotoxic test germination}

Our results showed that the four biochars enhanced the germination of cress. Indeed, the fresh weight was superior to the control. In fact, the fresh weight was $>80 \%$, meaning that the cress test is accepted according to Kehres et al. 2006. After 24 hours, the cress seeds were germinated. The dry and the fresh weight of the four biochars had not been shown any significance. Concerning, the length of hypocotyl, we noted that the high length was higher in walnut shells biochar following up by banana biochar, and monitoring by almond shells biochar. While, the lowest length of hypocotyl was from peanut hull biochar.

Cress was germinated in the four types of biochar which means that all biochars that we used didn't contain volatile compounds (Fig. 1). Indeed, every biochar must be analyzed, to assess its toxicity, before any field application. Our results showed germination of cress, which means that our peanut hull biochar is safe from toxic compounds such as PHA, PCB, and dioxins. That goes with the study of (Busch et al. 2012). Concerning the fresh weight of seedlings of peanut hull biochar treatments was $>80 \%$, which proves that no negative effect of volatiles substances on germination or growth. The same for almond shells biochar, cress was grown, which means no negative effect of the volatile compounds.

The principal component analysis was employed to determine the effects of the four biochar type on the barley germination test. Three variables WC, FW, and Germ_rate) are correlated

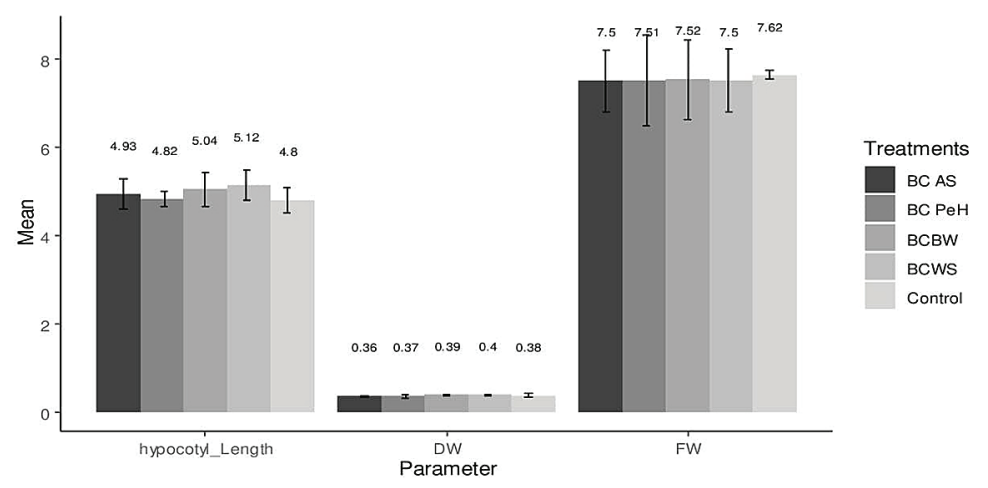

Fig. 1. The results of the Cress test: (FW) fresh weight, (DW) dry weight and length of the hypocotyl of the four biochars (BC-BW): banana biochar, BC-WS: walnut shells biochar, BC-PeH: peanut hull biochar, BC-Alm almond shells biochar), measured after 7 days (error bars equal to $95 \%$ confidence intervals)and the cress germination test was repeated four $(n=4)$. The difference in significance between the four biochars is showed by diverse means (one-way analysis of variance, ANOVA). 
with the first component, whereas the two variables (DW, and WUE) are correlated with the second component (Fig. 2), the information collected by the first component is independent of the second information collected by the two variables, so the two informations are complementary. Therefore, a good biochar classification must be given by the two pieces of information.

From the five parameters FW, DW, WC, WUE, and germination rate, it is clear that there were different clusters among the four biochars. To know the best biochar type and its impact on barley germination, a cluster analysis was conducted (Fig. 3). The cluster analysis led to the classification of the biochar types into five groups.

PCA based on the five parameters (Fig. 2) gave a result consistent with that of the cluster analysis. The cluster and PCA results highlighted five groups, for the $0 \mathrm{Alm}$ and $1 \mathrm{P}$ treatments group which mean $(0 \%$ of almond biochar and $1 \%$ peanut hull biochar respectively), the WUE and DW had the highest value while a low significance in the three variables (FW, WC, and Germ_rate). For contrast, it is clear from the biplot PCA that the treatments amended with the almond shells biochar didn't show strong growth for barley.

At all concentrations that we used $(1,2.5,5$, and $10 \%$ biochar-peat mixture), none of them revealed a negative effect on seed barley germination. Indeed, in this study, we based to compare the fresh and dry weight for the four biochars treatments with the control, which contain only peat, to indicate the presence of heavy metals and the toxicity of each biochar. In the banana biochar barley germination test, all treatments showed a high freshness as well as a higher growth rate of barley, while the $10 \%$ banana biochar treatment was better than the $5 \%$ banana biochar. These results are in line with (Bush et al. 2012) on who found that hydrochar affects barley germination by $10 \%$ and $25 \%$. The same result was occurred by (Bargmann et al. 2013), that some biochars have inhibited the germination of different plant species, and some hydrochars emitted the phytotoxic gases. While, the effect of peanut hull biochar on barley germination was efficient than the impact of banana biochar. Peanut hull biochar had a statistically significant impact on FW, WC and germination rate of barley, especially on fresh/dry weight in $2.5 \%$ and $10 \%$ treatments, and a low impact on barley germination in 1\% peat-peanut hull biochar application (Fig. 2). In contrast, it is clear from the biplot PCA that the treatments amended with the almond shells biochar didn't show strong growth for barley. Furthermore, the application of the four biochars enhanced the water content by $6 \%, 10 \%, 1 \%, 30 \%$ for banana biochar; peanut hull biochar, walnut shells biochar, and almond shells biochar respectively. Moreover, The application of the biochars increased the WUE by $7 \%, 25 \%, 5 \%$ for banana biochar; peanut hull biochar, and almond shells biochar respectively, although walnut shells biochar didn't increase the WUE.

The results of Table 1 reveal that all the factors have highly significant effect ( $p$-value $<0.0001$ ). In all three repeated tests, $8 \%$ banana biochar mixed with sand showed negative germination of Lactuca sativa, while lettuce has

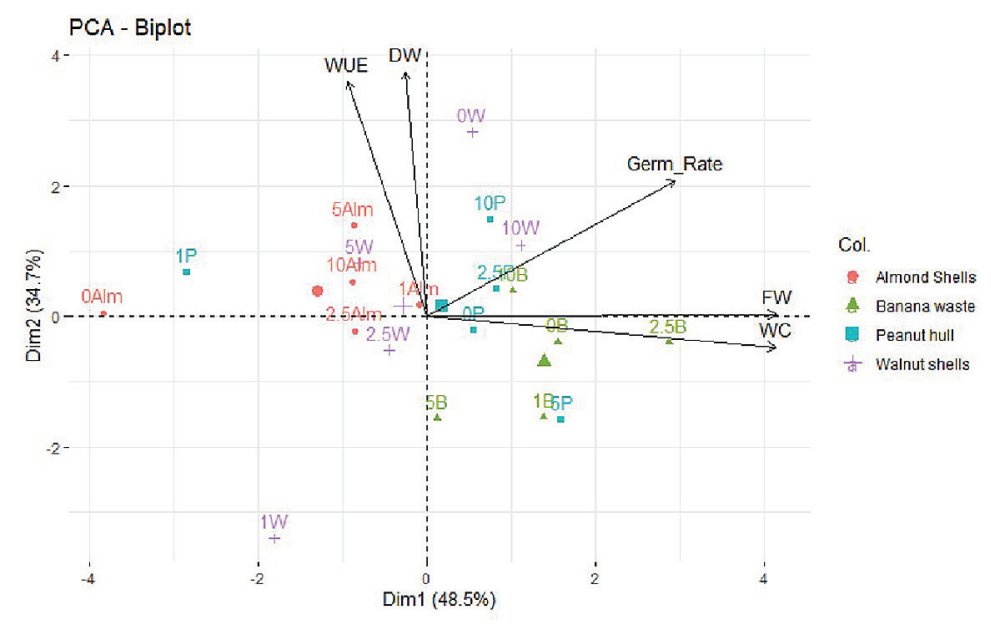

Fig. 2. PCA scatter plot (Biplot) showing the effect of the four biochars made by the four biomass (Almond shells, banana waste, peanut hull and walnut shells) on the five parameters of the barley germination test (WC:water content,DW:dry weight,FW:fresh weight,WUE:water-use efficiency,and Germ_Rate:germination rate) 


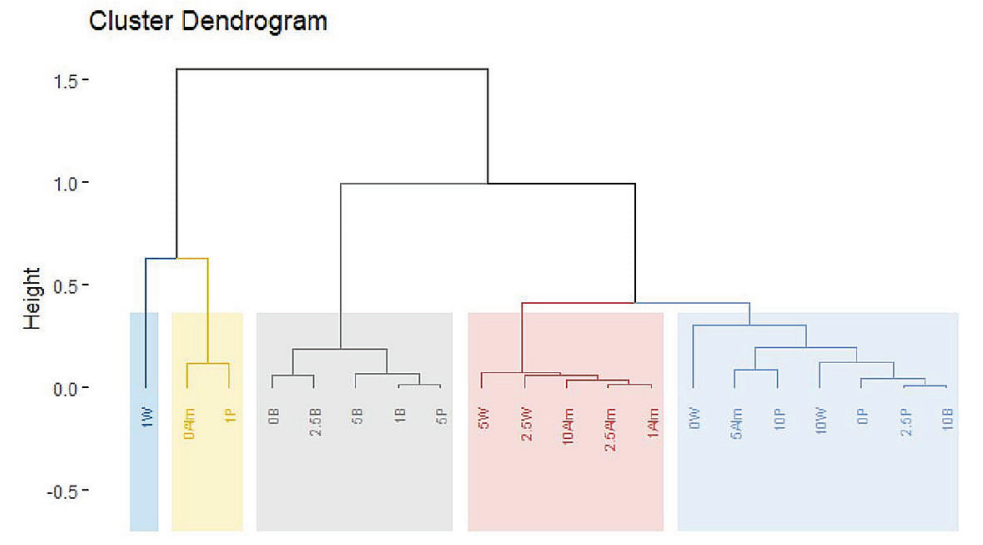

Fig. 3. Hierarchial cluster figure based on the effect of the four biochars (W: walnut shells biochar, Alm: almond shells biochar, B: banana waste biochar and P: peanut hull biochar) on the five parameters of a barley germination test

germinated even at an $8 \%$ rate on peanut hull biochar, almond shells biochar, and walnut shells biochar. In all treatments, the fresh weight of all seeds and the fresh weight per plant were smaller compared to the control and were zero at $8 \%$ of banana biochar, indeed, the scheffé test provides different groups of treatments as showed in Table 2.

In all treatments of sand mixed with peanut hull biochar, lettuce was germinated even at an $8 \%$ rate, the germination was higher, which means that peanut hull biochar didn't contain salt or any sensitive substances for salad germination. Our results are in line with the study of( Bush et al. 2012) in which they found that adding peanut hull biochar didn't have any negative effect on fresh weight seedlings and germination of Lactuca sativa seeds. In contrast, banana biochar inhibited the germination and fresh weight of lettuce, at the highest application rate of $8 \%$, also, the conductivity of the mixture of sand and banana biochar at $8 \%$ level was higher compared to other mixtures. The value was 2.21 $\mathrm{mS} / \mathrm{cm}$ (Table 3 ). This means that the mixture of sand and banana biochar contained salt or other substances that could be sensitive to the lettuce germination (Libra et al. 2011, Bouqbis et al.
2016). Also, the concentration and the type of PAH is influenced by the pyrolysis, the temperature and the type of biomass pyrolysis. The increase in the temperature of pyrolysis decreases the concentration of PAH, certain types of biomass produce more PAH compared to others during pyrolyze. The production of Pyrene is not influenced either by the temperature or by the nature of the pyrolyzed biomass, on the other hand, Naphthalene is the PAH most influenced by these two parameters (Freddo et al. 2012). Most biochars have a basic $\mathrm{pH}$ either in water or $\mathrm{NaCl}$ which can improve the $\mathrm{pH}$ of acid soils and eliminate its negative effects (Fidel et al. 2017). Heavy metals increase in biochars (Liu et al. 2014), but these metals are immobilized (Park et al. 2011). While other treatments of banana biochar $(0.5,1,2,4,6 \%)$ no negative effects were noticed. Some kinds of biochars having positive effects on the yields of certain crops in saline soils (Akhtar et al. 2015).

Furthermore, the fresh weight seedling which is the more sensitive parameter revealed a positive effect in all biochar treatments. The application of almond shells biochar increased the germination rate of all treatments. Also, it had enhanced $\mathrm{pH}$ after adding the almond shells biochar.

Table 1. Statistical results of Two-way ANOVA of the lettuce test germination

\begin{tabular}{|l|c|c|c|c|c|c|}
\hline \multirow{2}{*}{ Factors } & \multicolumn{2}{|c|}{ Fresh weight per plant } & \multicolumn{2}{c|}{ Germination rate } & \multicolumn{2}{c|}{ Fresh weight of all seeds } \\
\cline { 2 - 7 } & Fisher Value & p-value & Fisher Value & $p$-value & Fisher Value & $p$-value \\
\hline Treatments & 15,58 & $<0,0001$ & 9,00 & 0,00001 & 15,93 & $<0,0001$ \\
\hline BC & 46,26 & $<0,0001$ & 33,84 & $<0,0001$ & 44,14 & $<0,0001$ \\
\hline Treatments $\times$ BC & 11,13 & $<0,0001$ & 9,89 & $<0,0001$ & 8,61 & $<0,0001$ \\
\hline
\end{tabular}


Table 2 . Comparison of the means of the treatments by the sheffé test

\begin{tabular}{|l|c|c|c|c|c|c|}
\hline \multirow{2}{*}{ Treatments } & \multicolumn{2}{|c|}{ Fresh weight per plant } & \multicolumn{2}{c|}{ Germination rate } & \multicolumn{2}{c|}{ Fresh weight of all seeds } \\
\cline { 2 - 7 } & Value & Groups & Value & Groups & Value & Groups \\
\hline Ctr & 49,113 & A & 98,333 & A & 1,941 & A \\
\hline BC-PeH & 34,593 & B & 91,389 & A & 1,275 & B \\
\hline BC-WS & 34,180 & Bc & 92,206 & A & 1,376 & B \\
\hline BC-Alm & 33,162 & Bc & 93,472 & A & 1,238 & B \\
\hline BC-BW & 29,951 & C & 91,333 & B & 1,312 & B \\
\hline
\end{tabular}

\section{PHYSICAL AND CHEMICAL ANALYSES}

The physical and chemical properties of four biochars and sand collected from Taroudant are shown in Table 3. The $\mathrm{pH}$ values of all biochars were alkaline, ranging from 9.41 to 8.91 . The highest value ( $\mathrm{pH} 9.41)$ was observed in the walnut shells biochar formed at $256^{\circ} \mathrm{C}$, then the $\mathrm{pH}$ of the almond shells formed at $343{ }^{\circ} \mathrm{C}$. This goes with an increase in temperature of pyrolysis and a decrease in $\mathrm{pH}$ values (Celletti et al. 2020). The EC value was lower for the sand comparing to the four biochars. Furthermore, the mineral composition was higher for banana waste biochar than the others. Concerning heavy metals, the BC-WS and BC-Alm contents revealed the highest value. From, Table 3, it can be seen that the organic matter and organic carbon $(\mathrm{MOt} \%, \mathrm{CO} \%)$ were robust for the four biochars comparing to sand.
Our biochars materials produced from differents feedstocks containing banana waste, almond shells, walnut shells and peanut hull are characterized by strongly alkaline $\mathrm{pH}$ values and high EC values. This alkalinity is due to the type of feedstock and the temperature of pyrolysis (Chan et al. 2008). The alkaline biochars are recommended for the acidic soil because it enhances the $\mathrm{pH}$ of acidic soils.

The EC value was higher for banana waste biochar $(3.20 \mathrm{mS} / \mathrm{cm})$. Several studies revealed that the addition of biochar with high EC to soil enhances the salinity of low EC soils. (Chan et al. 2008). Indeed, this type of biochar will be recommended for sandy soils.

The higher value of $\mathrm{pH}$ and $\mathrm{EC}$ were due to the presence of salts and alkalinity. Furthermore, the K content of banana waste biochar was $8.56 \%$ followed by almond shells biochar, which

Table 3. Physical and chemical analyses of the four biochars and sand

\begin{tabular}{|c|c|c|c|c|c|}
\hline Specification & Sand & BC-BW & BC-Peh & BC-WS & BC-Alm \\
\hline $\mathrm{pH}$ & 9.02 & 9.30 & 9.22 & 9.41 & 8.91 \\
\hline $\mathrm{EC}(\mu \mathrm{S} / \mathrm{cm})$ & 23.50 & 3200 & 1136 & 715 & 703 \\
\hline MOT (\%) & 2.50 & 72.69 & 92.29 & 41.47 & 38.23 \\
\hline $\mathrm{CO}(\%)$ & 1.45 & 42.16 & 53.53 & 24.05 & 22.18 \\
\hline $\mathrm{N}$ & & 0.2408 & 0.4222 & 0.2377 & 0.179 \\
\hline Nt (\%) & 0.007 & 1.08 & 1.64 & 0.85 & 1.21 \\
\hline $\mathrm{C} / \mathrm{N}$ & 206.88 & 39.20 & 32.61 & 28.17 & 18.29 \\
\hline $\mathrm{P}_{2} \mathrm{O}_{5}\left(\mathrm{O} /{ }_{00}\right)$ & 0.201 & & & & \\
\hline $\mathrm{K} 2 \mathrm{O} \quad\left(0 /{ }_{00}\right)$ & 0.357 & & & & \\
\hline $\mathrm{Na}_{2} \mathrm{O}\left(\mathrm{O} /{ }_{00}\right)$ & 0.192 & & & & \\
\hline $\mathrm{CaO} \quad\left(0 /{ }_{00}\right)$ & 0.933 & & & & \\
\hline $\mathrm{MgO} \quad\left(0 / 0_{0}\right)$ & 0.391 & & & & \\
\hline $\mathrm{Pt}(\%)$ & & 0.27 & 0.23 & 0.2 & 0.36 \\
\hline $\mathrm{K}(\%)$ & & 8.56 & 2.21 & 0.16 & 7.7 \\
\hline $\mathrm{Na}(\%)$ & & 2.69 & 1.06 & 0.36 & 6.14 \\
\hline $\mathrm{Ca}(\%)$ & & 2.68 & 2.49 & 6.01 & 6.83 \\
\hline $\mathrm{Mg}(\%)$ & & 0.67 & 0.41 & 0.42 & 1.56 \\
\hline $\mathrm{Fe}(\mathrm{ppm})$ & 0.40 & 547 & 467.6 & 6079 & 1160.8 \\
\hline $\mathrm{Mn}(\mathrm{ppm})$ & 7.40 & 107.1 & 51.2 & 232.5 & 253.5 \\
\hline $\mathrm{Cu}(\mathrm{ppm})$ & 0.90 & 62.8 & 38.3 & 993.8 & 94.3 \\
\hline $\mathrm{Zn}(\mathrm{ppm})$ & 2.60 & 74 & 65.2 & 241.4 & 79.7 \\
\hline
\end{tabular}


means that those biochars can affect EC values (Uras et al. 2012).

Furthermore, we have found that the four biochars had relatively high $\mathrm{K}$ and $\mathrm{Na}$ content (Table 3).

However, many studies showed that some biochars can be contaminated during the pyrolysis process by dangerous inorganic substances (heavy metals) and organic ones (Hale et al. 2012; Oleszczuk et al. 2013; Buss and Masek 2014; Kołtowski and Oleszczuk 2015; Domene et al. 2015) which was the case in our study where

a)

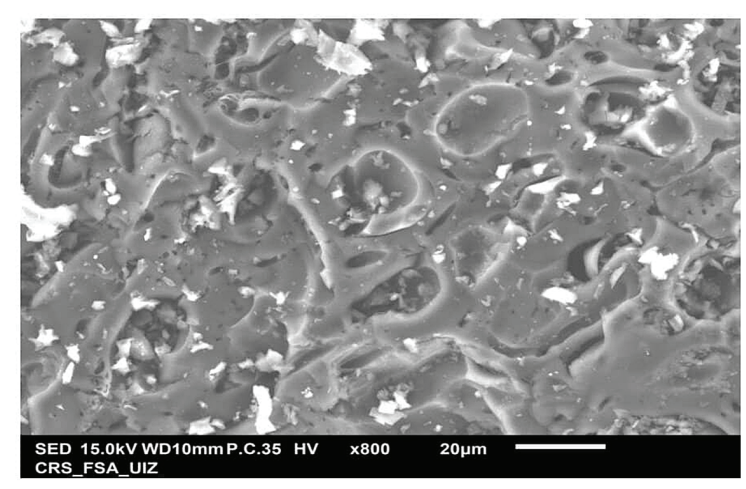

b)

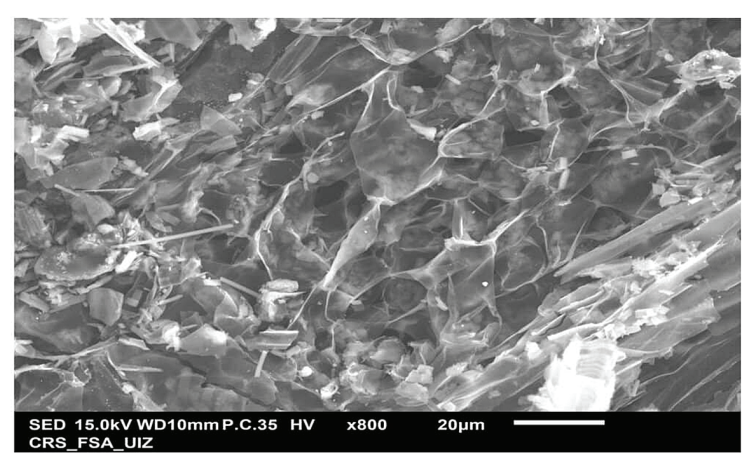

c)

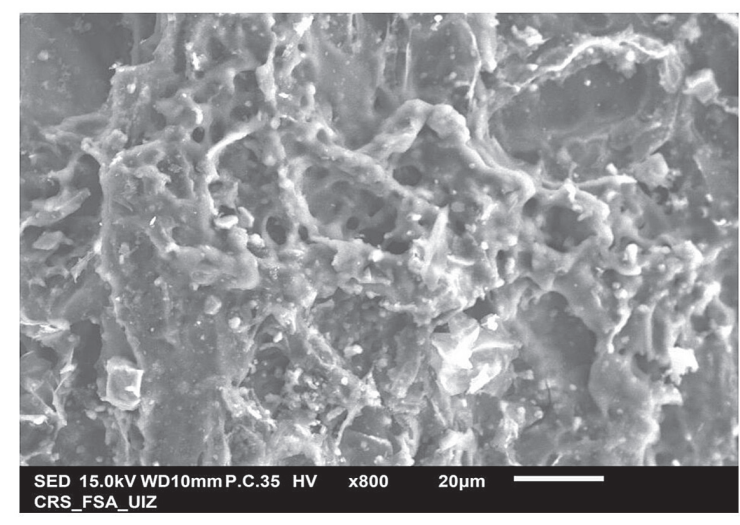

heavy metal contents were higher with the $\mathrm{BC}$ $\mathrm{WS}$ and $\mathrm{BC}-\mathrm{Alm}$ biochar.

\section{Morphological analyses}

The morphology of the four biochars (BCBW, BC-PeH, BC-WS moreover BC-Alm) was analyzed through SEM (Fig.4). Representative images illustrate the differences in microstructure beyond the four biochars, $\mathrm{BC}-\mathrm{BW}$ and $\mathrm{BC}$ $\mathrm{PeH}$ biochars showed distinct microspores. Also, the two biochars (BC-BW and $\mathrm{BC}-\mathrm{PeH}$ ) had a
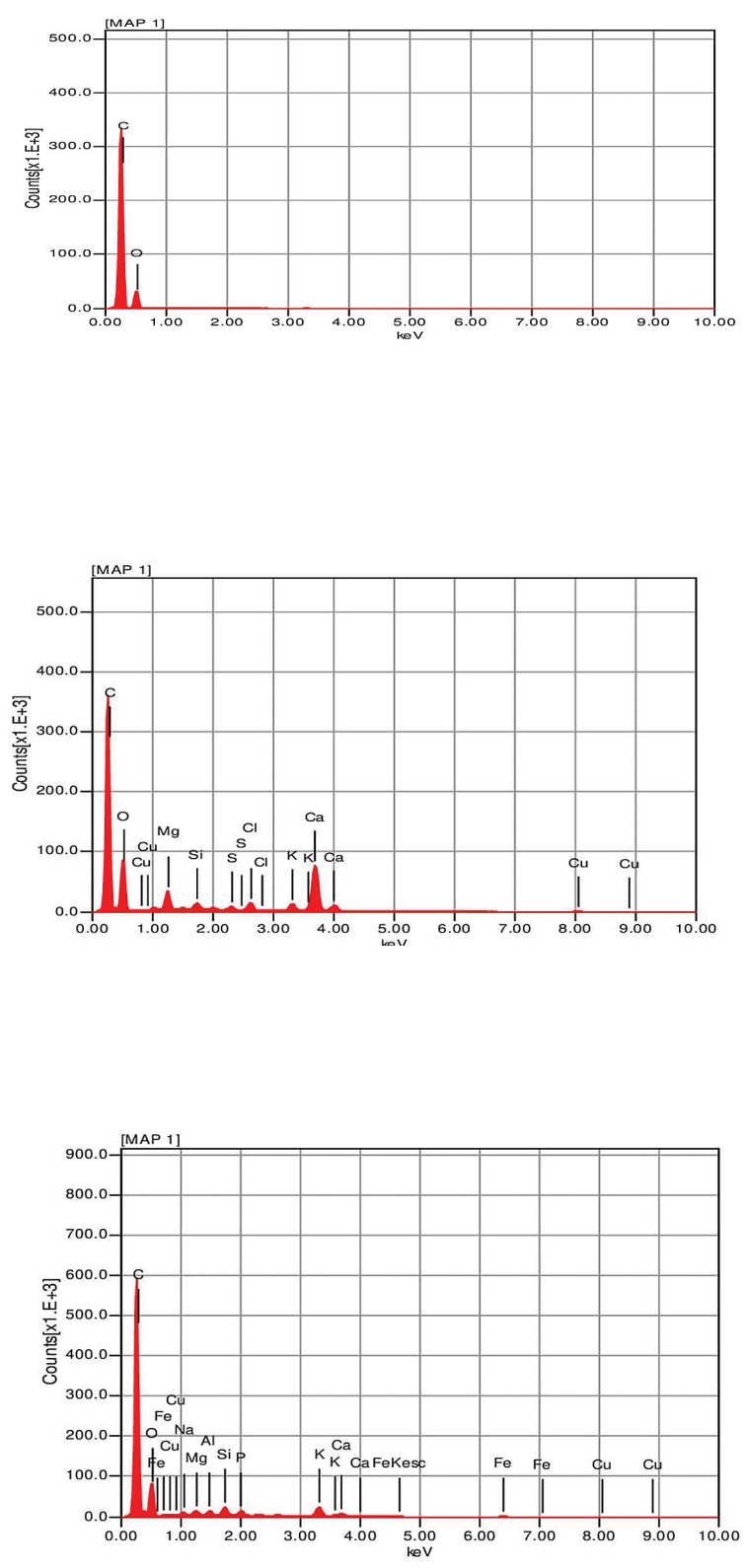
d)
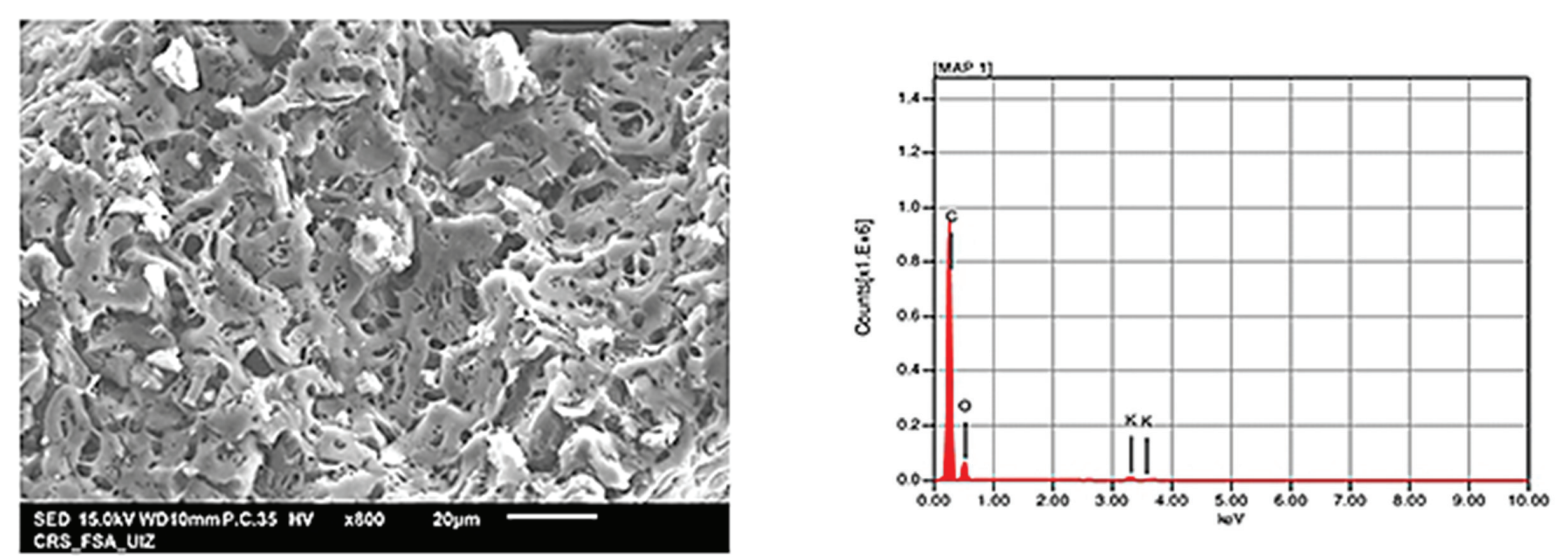

Fig. 4. scanning electron microscopy images and EDS spectra of fresh biochar (BC) showing: A) SEM and

A') EDS analysis for almond shells biochar. B) SEM and B') EDS analysis for banana waste biochar C) SEM and C') EDS analysis for peanut hull biochar.D) SEM and D') EDS analysis for walnut shells biochar.

considerable amount of mineral matter on their surface compared to the BC-WS and BC-Alm. Indeed, the EDS mapping of BC-PeH Biochar shows the appearance of Carbon (62.48\%), Oxygen $(25.81 \%)$, Sodium $(0.73 \%)$, Magnesium $(0.80 \%)$, Aluminum $(0.69 \%)$, Silicium $(1.52 \%)$, Phosphore (1.23\%), Potassium (3.76\%), Calcium $(1.45 \%)$, Iron $(0.64 \%)$, Copper $(0.88 \%)$. In addition the EDS spectrum of $\mathrm{BC}-\mathrm{BW}$ had a rich element contents which are Carbon (46.26\%), Oxygen (28.98\%), Magnesium (2.73\%), Silicium $(0.81 \%)$, Sulfur $(0.59 \%)$, Chlorine (1.48\%), Potassium (2.04\%), Calcium (16.15\%), Copper $(0.96 \%)$. In contrast, the EDS mapping of the BC Alm contains only Carbon (72.08\%), and Oxygen (27.92\%). Further, the EDS of walnut shells biochar BC-WS had shown besides Carbon (75.08\%), and Oxygen (23.41\%), Potassium $(1.51 \%)$. These results are in line with the previous study which reported the riches of biochar is due to the feedstock and the temperature. (Celletti et al. 2020). Moreover, the presence of microspore in biochars makes it very recommended in agriculture, which is remarkable in the treatments amended by the two biochars (BC-BW and BC$\mathrm{PeH}$ ) in our plant's germination (lettuce, barley, and lepidium germination test) (Bargmann et al. 2013, and Bouqbis et al. 2017).

\section{CONCLUSIONS}

Biochar had taken more and more attention, indeed it helps to repair degraded soils by fixing carbon, soil aggregation, and enhancing water holding capacity. In this survey; the four biochars obtained from different feedstocks increased the water holding capacity, the highest effect of improving WHC was observed at banana waste biochar comparing to other biochars, while for the phytotoxic test, lettuce didn't grow at the rate of $8 \%$ of banana waste biochar, which indicates that in this level the salinity was higher, although the three other types of biochars sprouted in all treatments, even in $8 \%$. Besides, the two biochars BC-Alm and BC-WS revealed the presence of heavy metals, while $\mathrm{BC}$ $\mathrm{BW}$ and $\mathrm{BC}-\mathrm{PeH}$ have shown many pores filled by elemental nutrient contents that's why it is necessary to assess biochar before any field application and to choose wisely the feedstock of biochar.

\section{Acknowledgments}

The author would like to thank the fellowship CNRST(Centre National de Recherche Scientifique et Technique, Morocco).

\section{REFERENCES}

1. Akhtar, S., Andersen, M., Liu, F. 2015.Residual effects of biochar on improving growth, physiology and yield of wheat under salt stress. Agricultural Water Management. 158, 61-68.

2. Bargmann, I., Rillig, M.C., Buss, W., Kruse, A., Kuecke, M. 2013. Hydrochar and Biochar Effects on Germination of Spring Barley. Journal of Agronomy and Crop Science. 199(5), 360-373.

3. Barrow, C.J. 2012. Biochar. Potential for countering land degradation and for improving agriculture. Applied Geography. 34, 21-280. 
4. Blakemore, L.C., Searle, P.L., Daly, B.K. 1987. Methods for Chemical Analysis of Soils. New Zealand Soil Bureau Scientific Report. 80, 103.

5. Boudergues, R., Calvet, H. 1970. Note sur la digestiblité des coques d'arachides utilisées en alimentation animale. I. Digestibilité In vitro. Revue d'Elevage et de Médecine Vétérinaire des Pays Tropicaux. 23, 493.

6. Bouqbis, L., Koyro, H. W., Harrouni, M. C., Daoud, S., Ainlhout, L. F. Z., Kammann, C. I. 2016. Effect of Two Different Biochars on Germination and Seedlings Growth of Salad, Cress and Barley. International Journal of Biological, Biomolecular, Agricultural, Food and Biotechnological Engineering.10(12), 1-9.

7. Bouqbis, L., Daoud, S., Koyro, H. W., Kammann, C. I., Ainlhout, F. Z., Harrouni, M. C. 2017. Phytotoxic effects of argan shell biochar on salad and barley germination. Agriculture and Natural Resources., 51(4), 247-252.

8. Busch, D., Kammann, C.,Grünhage, L., Müller, C. 2012. Simple biotoxicity tests for evaluation of carbonaceous soil additives: establishment and reproducibility of four test procedures. Journal of Environmental Quality, 41(4), 1023-1032.

9. Buss, W., Masek, O., 2014. Mobile organic compounds in biochar: a potential source of contamination phytotoxic effects on cress seed (Lepidium sativum) germination. Journal Environmental Management, 137, 111-119.

10. Chan, K.Y., Zwieten, L. Van., Meszaros,I., Downie, A., Joseph, S. 2008. Using poultry litter biochars as soil amendments. Australian Journal of Soil Research, 46, 437-444.

11. Chanakya, H. N., Sreesha, M.2012. Anaerobic retting of banana and are canut wastes in a plug flow digester for recovery of fiber, biogas and compost. Energy for Sustainable Development, 2(16), 231-235.

12. Celletti,S., Bergamo, A., Benedetti, V., Pecchi, M., Patuzzi, F., Basso, D., Baratieri, M., Cesco, S., Mimmo, T. 2020. Phytotoxicity of hydrochars obtained by hydrothermal carbonization of manure-based digestate, Journal of Environmental Management.

13. Cui, L., Yan, J., Yang, Y., Li, L., Quan, G., Ding, C., Chen, T., Fu, Q., Chang, A. 2013. Influence of Biochar on Microbial Activities of Heavy Metals Contaminated Paddy Fields. BioResources. 8(4), 5536-5548 .

14. Darley, E. F., Burleson, F. R., Mateer, E. H., Middleton, J. T., Osterli, V. P. 1966. Contribution of Burning of Agricultural Wastes to Photochemical Air Pollution. Journal of the Air Pollution Control Association, 16(12), 685-690 .

15. Domene, X., Enders, A., Hanley, K., Lehmann, J., 2015. Ecotoxicological characterization of biochars: role of feedstock and pyrolysis temperature.
Science Total Environmeent, 512, 552-561.

16. FAO 2018. Banana Market Review: Preliminary results for 2018. Rome. 12 pp. http://www.fao. org/fileadmin/templates/est/COMM_MARKETS_ MONITORING/Bananas/Documents/Banana_ Market_Review_Prelim_Results_2018.pdf

17. Fidel, R. B., Laird, D. A., Thompson, M. L. Lawrinenko, M. 2017. Characterization and quantification of biochar alkalinity. Chemosphere. 167, 367-373.

18. Foley, J. A., Ramankutty, N., Brauman, K. A.,Cassidy, Y. E. S., Gerber, J. S., Johnston, M., Mueller, N. D., O'Connell, C., Ray, D. K.,West, P. C., Balzer, C., Bennett, E. M., Carpenter, S. R., Hill, J., Monfreda, C.,Polasky, S., Rockström, J., Sheehan, J., Siebert, S., Tilman, D., Zaks, D. P. M. 2011. Solutions for a cultivated planet. Nature, 478(7369), 337-342.

19. Freddo, A., Cai, C. Reid, B. J. 2012.Environmental contextualisation of potential toxic elements and polycyclic aromatic hydrocarbons in biochar. Environmental Pollution, 171,18-24.

20. Glaser, B., Haumaier, L., Guggenberger, G., Zech, W. 2001. The 'Terra Preta' phenomenon: a model for sustainable agriculture in the humid tropics. Naturwissenschaften, 88(1), 37-41.

21. Glaser, B., Lehmann, J., Zech, W. 2002. Ameliorating physical and chemical properties of highly weathered soils in the tropics with charcoal - a review. Biology and Fertility of Soils, 35(4), 219-230.

22. Hale, S.E., Lehmann, J., Rutherford, D., Zimmerman, A.R., Bachmann, R.T.,Shitumbanuma, V., O'Toole, A., Sundqvist, K.L., et al., 2012. Quantifying the total and bioavailable polycyclic aromatic hydrocarbons and dioxins in biochars. Environmental Science \& Technology, 46 (17), 9333-9341.

23. Inyang, M., Dickenson, E. 2015.The potential role of biochar in the removal of organic and microbial contaminants from potable and reuse water: A review. Chemosphere, 134, 232-240.

24. Kammann, C. I., Linsel, S.,Gössling, J. W., Koyro, H. W. 2011. Influence of biochar on drought tolerance of Chenopodium quinoa Willd and on soilplant relations. Plant and Soil, 345 (1-2), 195-210.

25. Katyal, S., Thambimuthu, K., Valix, M.: Carbonisation of bagasse in a fixed bed reactor.2003. influence of process variables on char yield and characteristics. Renewable Energy, 28(5), 713-725.

26. Kehres, B., Th elen-Jüngling, M., Bidlingmaier, W., Meyer-Spasche, H., Fischer, P., Philipp, W., Marciniszyn, E., Schneichel, H-W., Severin, K., Müller, M. 2006. Methodenbuch zur Analyse organischer Düngemittel, Bodenverbesserungsmittel und Substrate. (Method handbook for analysis of organic fertilizers, soil ameliorants and substrates.). BundesgütegemeinschaftKompost 
e.V, Köln-Gremberghoven. https://scholar.google. com/scholar_lookup?title=Methodenbuch $\% 20$ zur $\% 20$ Analy se $\% 20$ organis cher $\% 20$ D\%C3\%BCngemittel\%2C\%20Bodenverbesserungsmittel $\% 20$ und $\% 20$ Substrate. $\% 20 \% 28$ Method $\% 20$ handbook $\% 20$ for $\% 20$ analysis $\% 20$ of $\% 20$ organic $\% 20$ fertilizers $\% 2 \mathrm{C} \% 20$ soil $\% 20$ ameliorants $\% 20$ and $\% 20$ substrates. $\% 29 \&$ publication_year $=2006 \&$ author $=$ Kehres $\% 2 \mathrm{CB} \&$ author $=$ Th $\% 20$ elen-

27. Koltowski, M., Moleszczuk, P.2015. Toxicity of biochars after polycyclic aromatic hydrocarbons removal by thermal treatment. Ecological Engineering, 75, 79-85.

28. Libra, J. A., Ro, K. S.,Kammann, C., Funke, A., Berge, N. D., Neubauer, Y., Titirici, M. M., Fühner, C.,Bens, O., Kern, J., Emmerich, K. H. 2011. Hydrothermal carbonization of biomass residuals: a comparative review of the chemistry, processes and applications of wet and dry pyrolysis. Biofuels, 2(1), 71-106.

29. Lachat Instruments, Milwaukee, WI, USA, Quik Chem Method. 1998a.13-107-06-2-D.

30. Lachat Instruments, Milwaukee, WI, USA, Quik Chem Method. 1998b.13-115-01-1-B

31. Lindsay, W.L. \& Norvell, W.A. 1978. Development of a DTPA soil test for zinc, iron, manganese and copper. Soil Science Society of America Journal, $42,421-428$.

32. Liu, T., Liu, B., Zhang, W. 2014. Nutrients and Heavy Metals in Biochar Produced by Sewage Sludge Pyrolysis: Its Application in Soil Amendment. Polish Journal of Environmental Studies, 23(1), 271-275.

33. Mahhou, A., Dennis, F. G.1992. The Almond in Morocco. Horttechnology, 2(4), 488-492.

34. Oukabli, A. Mamouni,A.2006. Le Noyer: Pour une diversification fruitière rentable. Transfert de Technologie en Agriculture Maroc, https://www.agrimaroc.net/bulletins/btta_139.pdf.

35. Oleszczuk, P., Josko, I., Kusmierz, M., 2013. Biochar properties regarding to contaminants content and ecotoxicological assessment. Journal of Hazardous Materials, 260, 375-382.

36. Park, J. H., Choppala, G. K., Bolan, N. S., Chung, J. W. Chuasavathi, T. 2011. Biochar reduces the bioavailability and phytotoxicity of heavy metals. Plant and Soil. 348(1), 439-451.

37. Peigné, J.,Girardin, P. 2004. Environmental Impacts of Farm-Scale Composting Practices. Water Air and Soil Pollution, 153(1), 45-68.

38. Saeed, M. A., Medina, C. H., Andrews, G. E., Phylaktou, H. N., Slatter, D., Gibbs, B. M. 2014. Agricultural waste pulverised biomass: MEC and flame speeds. Journal of Loss Prevention in the Process Industries, 36, 308-317.

39. Tamburino, L., Bravo, G., Clough, Y., Nicholas, K. A. 2020. From population to production: 50 years of scientific literature on how to feed the world. Global Food Security,24, 100346.

40. Tanji, A., Benicha, M., Mrabet, R. 2011. Techniques de production de l'arachide: Résultats d'enquêtes au Loukkos. Transfert de Technologie en Agriculture Maroc, http:/webagris.inra.ma/doc/tanji09111.pdf.

41. Uras, Ü., Carrier,M., Hardie, A. G.,Knoetze, J. H. 2012. Physico-chemical characterization of biochars from vacuum pyrolysis of South African agricultural wastes for application as soil amendments. Journal of Analytical and Applied Pyrolysis 98, 207-213.

42. Van Rast, E., Verloo, M., Demeyer, A., Pauwels, J.M. 1999. Manual for the Soil Chemistry and Fertility Laboratory.

43. Walali, L. D., Skiredj, A.,Elattir, H. 2003. L'amandier, l'olivier, le figuier, le grenadier. Transfert de Technologie en Agriculture Maroc, https:// www.agrimaroc.net/bulletins/btta_105.pdf.

44. Zhang, D., Pan, G., Wu, G., Kibue, G. W., Li, L., Zhang, X., Zheng, J., Zheng, J., Cheng, K., Joseph, S., Liu, X. 2016. Biochar helps enhance maize productivity and reduce greenhouse gas emissions under balanced fertilization in a rainfed low fertility inceptisol. Chemosphere, 142, 106-113. 